\title{
ERP Correlates of Transposed-Letter Effects in Uyghur Using Arabic Alphabet
}

\author{
Binuer SU, Minghu JIANG, Abudoukelimu ABULIZI \\ Center for Psychology and Cognitive Science, Lab of Computational Linguistics, School of Humanities, \\ Tsinghua Univ., Beijing 10084, China
}

\begin{abstract}
Recent research has shown that pseudowords created by transposing two nonadjacent letters are perceptually similar to their base words. Our aims are to expolore the issues: (1) whether the transposed-letter effect (TL effect) can be generalized to any type of alphabetic scripts; (2) whether the pseudowords transposing two consonants are more similar to their base words compared with those transposing vowels. We report one lexical decision task experiment in which pseudowords are created by transposing or replacing two consonants or two vowels in Uygur script ---- a linear writing system using Arabic alphabet, employing Event Related potentials (ERPs). Our experimental results show a significant variation between the modulation of the amplitude of the N400 components of the transposed-letter pseudowords and the replaced-letter pseudowords, which did not occur in Arabic language. Furthermore, the modulation differs from that of transposed consonants and vowels. These results suggest that visual words coding computational models are exclusive to linear scripts. And functional distinction between consonants and vowels processing indeed exists in languages using Arabic alphabet.
\end{abstract}

KEYWORD: Transposed-letter effect; Evidence-related potentials; Uygur language; consonants and vowels processing

\section{INTRODUCTION}

It is common in reading that word like "judge" is often confused with its misspelt word "jugde" (Chanbers, 1979). In that matter, transposing two letters in a word activates the similar perception of this word, which is called transposed-letter effect (TL effect).

To capture the TL effect, a number of coding computational models have been proposed, like SOREL model (Witney, 2001), and overlap model (Gomez et al., 2008), which insist that the identity and the position of letters are not established in parallel in visual word processing. It is an overlap model that is commonly acknowledged input coding scheme. It assumes that each letter in the letter string links with more than one positions, and how strongly connection is depends on the distance of the correct position and other positions. For instance, the letter $\mathrm{D}$ in the position three in the word JUDGE associates more closely with the position two and four than the position one and five.

Generalizations of TL effects and the computational models are key issues of current research. TL effects have been revealed firmly when not only the adjacent letters but also the nonadjacent letters were transposed in linear scripts like English
(Schoonbaert et al., 2004) and Spanish (Perea, 2004) using the Latin alphabet.

A question then arises as to a functional difference between consonants and vowels in visual word recognition. Recent research focuses on the difference between the processing of consonant and vowel letters. Peréa reported masked priming effects for consonant transpositions (relovucion REVOLUCION) but not vowel transpositions (revulocion - REVOLUCION) (Carreiras et al., 2009).

In fact, there is not any research on TL effects in Altaic languages. So Uygur language, which belongs to Altaic languages similar with Korean, using Arabic-based alphabet, is a proper one to verify the generalizations of TL effects and recognition models.

In sum, by transposing two nonadjacent consonants or two vowels versus replacing two consonants or vowels in Uygur words while ERPs are recorded, we expect the significant variation between the N400 components of replaced-letter pseudowords and transposed-letter pseudowords. 


\section{METHOD}

\subsection{Pariticipants}

Twenty-two (ten women) students from universities in Beijing took part in the experiment voluntarily. All of them are native Uygur language speakers having no history of mental disease and having normal or correct-to-normal version. All participants are right-handed.

\subsection{Materials}

We chose 150 daily Uyghur words carefully as our base words. The mean frequency of these words was 34.9 in per one million (range: 1-178.5) in the unpublished Uyghur database of famous novels in Uyghur language. The mean letter length was 8.2 (range: 7-9). We created four pseudowords for each base word "مؤدايِينه" ("protect") [mudapiye]: (1) transposing two nonadjacent consonant letters "مؤُبادبيه" [mupadiye], (2) transposing two nonadjacent vowel letters "مؤدبِايه" [mudipaye], (3) replacing two nonadjacent consonant letters by other consonant letters "مؤرابيه، [murabiye], and (4) replacing two nonadjacent vowel letters by other vowel letters "مؤدديويه" [mudepoye]. In all above, the first syllable of the base word was not changed. 150 daily Uyghur words 7 to 9 letters long which had the same structure and the frequency with the base words were added to the materials as the additional words. Each pseudoword appeared one time in a different condition. All of the words were displayed randomly for each participant.

\subsection{Procedure}

Participants were arranged to a dark and quiet room. All words and pseudowords were displayed in white 24-font Uygur against grey background in a monitor in front of the participant. Participants were required to respond as quickly and accurately as possible whether the stimuli presented in the monitor were true words or not by pressing the buttons in a gamepad. For half of the participants left button was a symbol of "Yes" response and right button was a symbol of "No" response. For the remaining participants the order was reversed. All of the stimuli were divided into four blocks. On each trial, sequence was started with a fixation point ("+") in red remained for $500 \mathrm{~ms}$. Following the fixation point, there was a stimulus remained for $400 \mathrm{~ms}$. Next, double question mark ("??") was presented for $1300 \mathrm{~ms}$. And each trial ended with an empty screen in grey for $1000 \mathrm{~ms}$. Participants can blink if they are tired in this empty screen to avoid eye-movements and blinks during the interval from the fixation point until response was given. The stimuli were displayed randomly for each participant. And twenty warm-up trials in which the stimuli were different from the experimental trials were provided at the begging of the session and repeated if necessary to ascertain that participants fully understand the process of the experiment.

\subsection{EEG recording and analyses}

EEG data were collected from $64 \mathrm{Ag} / \mathrm{AgC1}$ electrodes (sampled at $500 \mathrm{~Hz}$, band-pass filtering= $0.1-100 \mathrm{~Hz}$, notch filtering $=50 \mathrm{~Hz}$ ) in a BP (Brain Product $\mathrm{GmbH}$, Munich, Germany) head-cap on the scalp, according to the international 10/20 system. One loose lead electrode was placed below the left eye to measure vertical electrooculography (EOG), and horizontal eye movements were monitored using another electrode placed on the outer canthi of right eye. The electrode FCz was used as reference. And it was re-referenced off-line to mastoids when data were recording. Electrode impedances were below $10 \mathrm{~K} \Omega$ for all channels. The Brain Vision Recorder software (Brain products, Munich, Germany) was used for data recording on PC running under Windows XP operating system.

EEG data were analyzed by Brain Vision Analyzer software BP (Brain Product $\mathrm{GmbH}$, Munich, Germany), and eye blinks were removed from further analyses. Two subjects' data were rejected from analysis due to high eye blinks. Filter high-pass $0.01 \mathrm{~Hz} / 24$ and low-pass $30 \mathrm{~Hz} / 24$ were applied. Epochs of $1000 \mathrm{~ms}$ were computed with a $200 \mathrm{~ms}$ pre-stimulus baseline. The data of ERPS were built on each of the experimental conditions, each of the subjects, and each of the electrode sides. Seven regions were computed out of the mean amplitude values of a serious of electrodes. The regions were: left-frontal region $(\mathrm{F} 1, \mathrm{~F} 3, \mathrm{~F} 5, \mathrm{FC} 1$, FC3, and FC5), left-central region (C1, C3, C5, CP1, $\mathrm{CP} 3$, and $\mathrm{CP} 5)$, left-posterior region (P1, P3, P5, $\mathrm{PO} 3, \mathrm{PO} 7$, and $\mathrm{O} 1)$, right-frontal region $(\mathrm{F} 2, \mathrm{~F} 4, \mathrm{~F} 6$, FC2, FC4, and FC6), left-central region (C2, C4, C6, $\mathrm{CP} 2, \mathrm{CP} 4$, and $\mathrm{CP} 6)$, left-posterior region (P2, $\mathrm{P} 4$, $\mathrm{P} 6, \mathrm{PO} 4, \mathrm{PO} 8$, and O2). Data were submitted to a repeated-measure ANOVA with electrode regions (frontal, central and posterior), hemisphere (left/right), and the experimental conditions (transposition versus replacement, consonant versus vowel) as independent factors. Time windows (300$500 \mathrm{~ms}$ and $500-650 \mathrm{~ms}$ ) selection was based on visual inspection.

\section{RESULTS}

We present the ERP grand averages of the pseudowords in Figure 3 of twelve recording sites. The amplitude of the N400 component is larger for transposed-letter pseudowords than for the replacedletter pseudowords in time windows $300-500 \mathrm{~ms}$ and 500-650 ms. The negative of transposed consonants 
is larger than that of transposed vowels in time window 300-500. The statistic analyses performed on the data of the mean values of electrodes are the evidence of this discovery.

The main effect of type of pseudowords in time window 300-500 ms was significant $[\mathrm{F}(1,19)$ $=5.086, \mathrm{p}=.036, \mathrm{p}<.05]$. The interaction effect of type of pseudowords $\times$ regions $[\mathrm{F}(2,38)=5.167, \mathrm{p}$ $=.016]$ was significant. The main effect of type of transposed letters was significant $[\mathrm{F}(1,19)=7.964$, $\mathrm{p}=.011, \mathrm{p}<.02]$. None of the interactions was significant. However, the main effect of replaced letters was not significant.

The main effect of type of pseudowords in time window 500-650 ms was significant $[\mathrm{F}(1,19)$ $=3.143, \mathrm{p}=.032, \mathrm{p}<.05]$. None of the interactions was significant. The main effect of type of transposed/replaced letters was not significant as well as interactions.
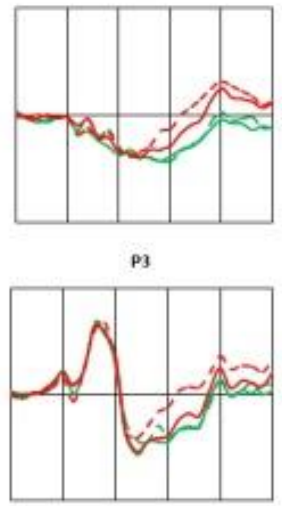

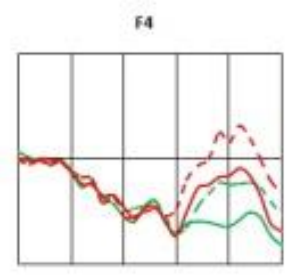

C4
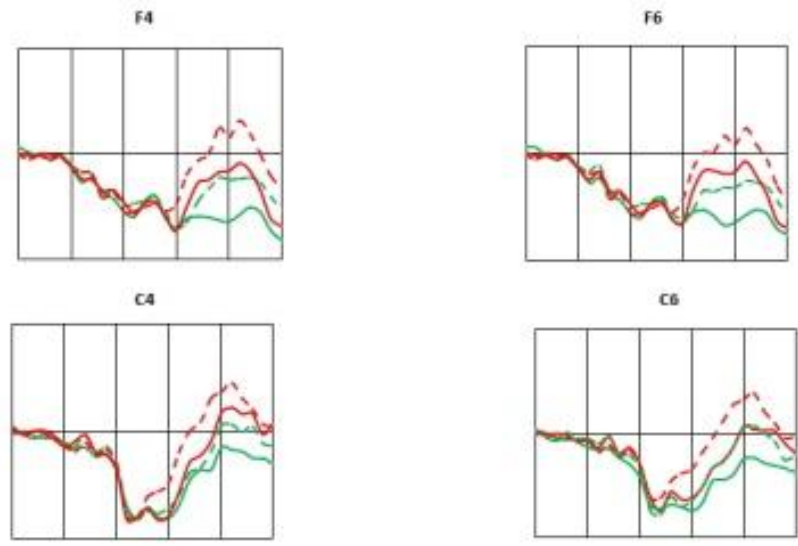

ce

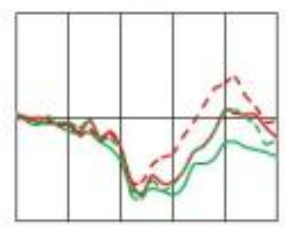

P4
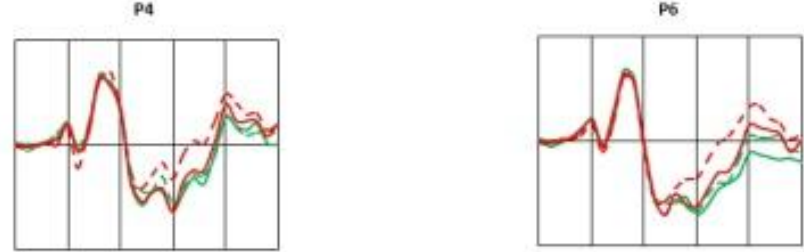
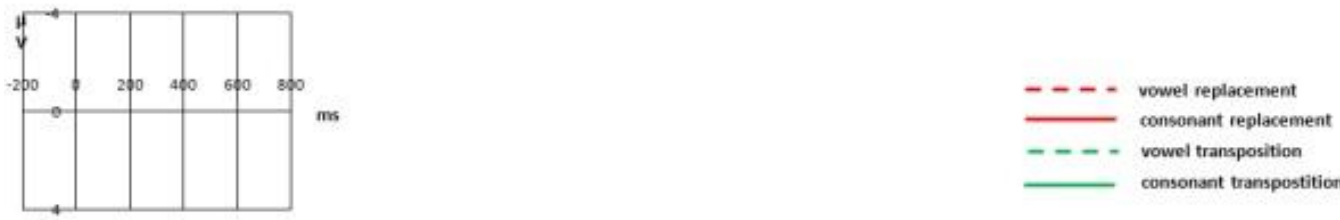

Figure 1. Ground average ERPs to four pseudowords: replaced-vowel, replaced-consonant, transposed-vowel, transposed-consonant from two representative electrodes of each region.

\section{DISCUSSION}

We found N400 for all types of pseudowords in the ERPs. There were significant variations between the amplitudes of $\mathrm{N} 400$ for transposed-letter pseudowords and replaced-letter pseudowords. In addition, there were significant variations between the amplitudes of N400 for transposed-consonantletter pseudowords and transposed-vowel-letter pseudowords. From EEG data, as expected, we observed firm nonadjacent transposed-letter effect in Uyghur language when transpositions generate congruent-syllable pseudowords. And it especially occurred in transposed-consonant letters. Consistent with the results of present research in other linear scripts (Perea et al., 2004), transposed-nonadjacentletter pseudowords in Uyghur language were regarded as their original words when the stimuli were quickly presented, which showed robust transposed-letter effect occurred in Uyghur language especially in consonants. However, when the time for recalling is provided, participants still do not recognize the mistakes they have made, which means robust transposed-letter effect occurs in Uygur language especially in consonants. Furthermore, functional distinction of consonants and vowels processing also presented in Uyghur language, despite that Uyghur script originates in Arabic script in which vowel letters are absent.

The results show that (1) transposed-letter pseudowords produced less negative amplitudes than replaced-letter pseudowords when transposed-letter; (2) the time course and spatial distribution of transposed-letter pseudowords differed from those of replaced-letter pseudowords; (3) transpositions of consonants produced less negative amplitudes than those of vowels. 
Taken together, present discoveries can be considered as supplements and challenges for existing studies. Robust transposed-letter effects occurred in linear scripts like English and Spanish (Carreiras et al., 2008, Perea et al. 2004, Schoonbaert et al., 2004, Stevens et al., 2003). Although Uyghur script is an evolution of Arabic, in which TL effect do not occur, the spatial characteristic of Uygur script has developed from planar or non-linear script like Arabic into linear script like English. TL effects also do not occur in Korean belonging to Altaic language family like Uyghur language and using Hangul script (Chang et al. 2009), which is argued by the syllable structure. Both of Arabic and Hangul scripts are non-linear scripts, which should be the primary factor of absence of TL effects in these languages. It is urgent to extend computational models of visual word recognition to fit non-linear scripts like Arabic and Korean.

\section{CONCLUSIONS}

From the experimental results, we observed that distinction of consonants and vowels is not special to Latin alphabet. The variation of these two letter clusters in Uyghur script using Arabic alphabet can be the evidence to prove that prosodic processing involves into visual word recognition. So we carefully proposed that functional distinction of consonants and vowels processing should be considered as supplements of computational models. And It is necessary for computational models to make room for prosodic processing in visual word recognition.

\section{ACKNOWLEDGEMENTS}

This work was supported by the National Natural Science Fund (61171114) and Key Fund (61433015), and National Social Science Major Fund (14ZDB154) of China.

\section{REFERENCES}

[1] Carreiras, M., Price, C., J. (2008). Brain activation for consonants and vowels. Cerebral cortex 18: 1727-1735.

[2] Carreiras, M., Vergara, M., Perea, M. (2009). ERP correlates of transposed-letter priming effects: The role of vowels and versus consonants. Psychophysiology 46: 3442 .

[3] Chambers, S. M. (1979). Letter and order information in lexical access. Journal of Verbal learning and Verbal Behavior 18: 225-241.

[4] Chang, H. L., Taft, M. (2009) Are onsets and codas important in processing letter position? A comparison of TL effects in English and Korea, Journal of Memory and Language. 60: 530-542.

[5] Gomez, P., Patcliff, R., and Peréa, M. (2008). The overlap model: A model of letter position coding, Psychological Review 115: 577-601.

[6] Perea, M., Lupker, S. J. (2004). Can CANISO activate CASINO? Transposed-letter similarity effects with nonadjacent letter positions. Journal of Memory and Language 51: 231-246.

[7] Schoonbaert, S. Grainger, J. (2004). Letter position coding in printed word perception: Effects of repeated and transposed letters. Language and Cognitive Processes 19: 333-367.

[8] Stevens, M., Grainger, J. (2003). Letter visibility and the viewing position effect in visual word recognition.

[9] Whitney, C. (2001). How the brain encodes the order of letters in a printed word: The SERIOL model and selective literature review. Psychonomic Bulletin and Review 8: 221-243. 